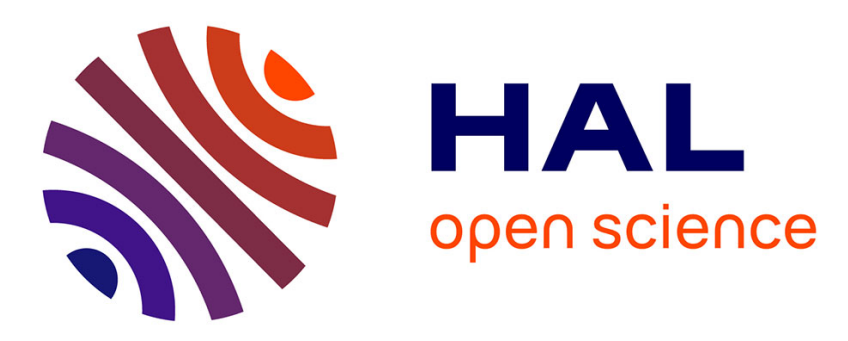

\title{
Differences in ability of jennies and mares to conceive with cooled and frozen semen containing glycerol or not
}

Marianne Vidament, P. Vincent, F.X. Martin, Michèle Magistrini, Elisabeth Blesbois

\section{- To cite this version:}

Marianne Vidament, P. Vincent, F.X. Martin, Michèle Magistrini, Elisabeth Blesbois. Differences in ability of jennies and mares to conceive with cooled and frozen semen containing glycerol or not. Animal Reproduction Science, 2009, 112 (1-2), pp.22-35. 10.1016/j.anireprosci.2008.03.016 . hal02665165

\section{HAL Id: hal-02665165 \\ https://hal.inrae.fr/hal-02665165}

Submitted on 31 May 2020

HAL is a multi-disciplinary open access archive for the deposit and dissemination of scientific research documents, whether they are published or not. The documents may come from teaching and research institutions in France or abroad, or from public or private research centers.
L'archive ouverte pluridisciplinaire HAL, est destinée au dépôt et à la diffusion de documents scientifiques de niveau recherche, publiés ou non, émanant des établissements d'enseignement et de recherche français ou étrangers, des laboratoires publics ou privés. 


\title{
Differences in ability of jennies and mares to conceive with cooled and frozen semen containing glycerol or not
}

\author{
Marianne VIDAMENT ${ }^{(1)}$, Pierrick VINCENT ${ }^{(2)}$, François-Xavier MARTIN ${ }^{(3)}$, \\ Michele MAGISTRINI (1), Elisabeth BLESBOIS ${ }^{(1)}$
}

(1) INRA, UMR0085, UMR INRA / CNRS / Haras Nationaux / Univ. Tours : Physiologie de la Reproduction et des Comportements, Physiologie Animale et Systèmes d'Elevage, Centre de recherche de Tours, NOUZILLY, 37380, FRA

(2) Les Haras Nationaux, Direction des Services et des Sites, Secteur Centre-Ouest, 17017 Saintes, FRA

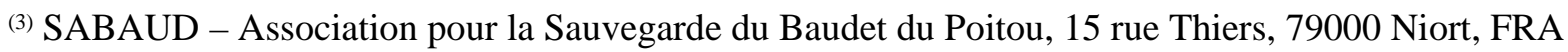

Corresponding author: M. Vidament, PRC, INRA, 37380 Nouzilly, France tel: 33247427805 fax: 33247427743 vidament@tours.inra.fr

Keywords: Fertility; Ass; Donkey; Jack; Stallion; Horse, Equine; Spermatozoa; Sperm; Cryopreservation; Dimethylformamide; DMF; Ethylene glycol;

Grant support: This study was supported by Les Haras Nationaux (French National Studs), the Association SABAUD (Association for the Preservation of Baudet du Poitou), the Bureau des Ressources Génétiques (French National Office of Genetic Resources, Program N¹09), and the Parc Régional du Marais Poitevin.

\begin{abstract}
A suitable method for the cryopreservation of donkey semen would be very valuable for the ex situ management of genetic diversity in this species. This report uses a variety of observation and trials to evaluate the effect of cryoprotectants in per cycle pregnancy rates (PC) in equids females (jennies (donkey) and mares (horse)). This was explored by 1 ) comparing the results of insemination of jennies and mares with cooled or frozen donkey semen, 2) examining the possible toxic effect of the cryoprotectant (CPA) glycerol in these two species and 3) studying alternative solutions.

Donkey and horse semen was either used immediately, or cooled according to some steps of the pre-freezing procedure or frozen and thawed. The pre-freezing procedure included semen dilution, centrifugation, resuspension in milk or in INRA82 $+2 \%$ egg yolk + various \% CPA (expressed as final concentrations in extended semen (v/v)) and then cooling to $4^{\circ} \mathrm{C}$.

PC was similar in mares and jennies inseminated with donkey semen cooled to $4^{\circ} \mathrm{C}$ in milk. However the PC was significantly higher in mares than in jennies when donkey semen was frozen with $2.2 \%$ glycerol $(36 \%, \mathrm{n}=50$ cycles vs $11 \%, \mathrm{n}=38$ cycles; $\mathrm{P}<0.01)$.

Increasing the concentrations of glycerol (0, 2.2, 3.5, $4.8 \%)$ before cooling stallion semen resulted in a progressive decrease in mare PC $(87,53,53,13 \%$ ( $\mathrm{n}=15$ cycles for each concentration); $\mathrm{P}<0.0001)$.

The addition of $2.2 \%$ glycerol before cooling donkey semen decreased the PC measured in jennies to 0 . The replacement of glycerol by $2 \%$ dimethylformamide increased the fertility obtained in jennies with cooled donkey semen (PC: 67\%, $\mathrm{n}=12$ cycles) but did not increase the fertility obtained with frozen-thawed donkey semen (PC: $11 \%, n=28$ cycles with dimethylformamide vs $0 \%, \mathrm{n}=16$ cycles with glycerol).
\end{abstract}

In conclusion, this study clearly shows that the ability of jennies to conceive after AI with donkey frozen semen is lower than that of mares. Glycerol affects the fertility of donkey and 
stallion spermatozoa as early as during the pre-freezing procedure. In consequence, the glycerol level must be low in frozen equine semen to provide good fertility. The toxic dose of glycerol for donkey spermatozoa seems to be almost half that for stallion spermatozoa. Whether this greater sensitivity of donkey spermatozoa to glycerol is responsible for the low success of semen cryopreservation in jennies is not so obvious because replacement of glycerol by dimethylformamide was not much more effective in terms of fertility.

\section{Introduction}

The donkey species is mainly distributed in small and often consanguine and endangered breeds in Europe. For example, 7 breeds with approximately 13 to 191 births per year per breed were reported in France in 2004 (Baudet du Poitou (BdP), Grand Noir du Berry, du Cotentin, de Provence, du Bourbonnais, Pyrénéen and Normand). A suitable method for cryopreservation of donkey semen would therefore be very valuable for the ex situ management of genetic diversity in this species. Nevertheless, very few laboratories have studied the technology of donkey semen cryopreservation (Glatzel et al. 1981, Piao, 1988, Trimeche et al., 1996, 1998, Silva et al., 1997) until recently (Oliveira et al., 2006, Alvarez et al., 2006), and often for the production of mules (donkey male x mares (= horse females)). The methods used for donkey semen are usually derived from those used for stallion semen. A method derived from the French stallion technique (Palmer, 1984) but using a higher amount of glycerol, the addition of glutamine and quail egg yolk instead of hen egg yolk was suggested by Trimeche et al. (1998). However pregnancies in jennies (= donkey females) were obtained only after redilution of the semen after thawing. Oliveira et al. (2006) recently failed to obtain pregnancies in jennies inseminated with semen frozen with different combinations of cryoprotectants (CPAs).

Although glycerol added to spermatozoa of numerous species before freezing provides good post-thaw motility, its negative effect on fertility has been clearly demonstrated in chickens (Hammersted \& Graham, 1992). The negative effect of glycerol on fertility in mares has been suspected for several years (Pace \& Sullivan, 1975, Pickett et al., 1975, Palmer, 1984) and such toxicity may also be questioned in donkeys. Glycerol removal from frozen chicken spermatozoa by dilution and washing, dialysis or centrifugation gradient as part of the thawing process restores their fertilizing capacity. The use of alternative CPAs such as dimethylacetamide (DMA) without removal at thawing also gives good results in this species (Challah et al., 1999; Tselutin et al., 1999).

Dimethylformamide (DMF) (Vidament et al. 2002, Squires et al. 2004, Alvarenga et al. 2005) and ethylene glycol (EG) (Ball et al. 2001, Mantovani et al, 2002, Squires et al. 2004) have also been proposed to replace glycerol for freezing semen in the horse with variable success rates reported.

The aim of the present study was to demonstrate the low fertility observed in jennies inseminated with frozen semen and to examine whether this was related to the use of the CPA glycerol. This was explored by 1) comparing the results of insemination of jennies and mares with cooled and frozen donkey semen, 2) examining the possible toxic effects of glycerol in these two species and 3) studying alternative solutions.

\section{Materials and Methods}

\subsection{Animals}

The 13 donkey males used in this study were from different breeds: 11 Baudet du Poitou (BdP) ( $500 \mathrm{~kg}), 1$ Grand Noir du Berry ( $400 \mathrm{~kg}$ ) and 1 Pyrénéen ( $350 \mathrm{~kg})$. All males 
belonged to Les Haras Nationaux (French National Studs) or to SABAUD (French Association of Preservation of Baudet du Poitou) and were housed individually. Thirty-five field jennies and 62 jennies (BdP or undefined breed) housed at the donkey centre of Dampierre (in which comparative trials were performed) were used.

Three male Welsh ponies were housed individually at INRA Nouzilly. Ninety female Welsh ponies (250-450 kg) were housed in pens of 4-5 at INRA Nouzilly. Mares (light and draught breeds) were managed in field practice.

\section{2. Semen preparation}

Semen was collected routinely with a closed-ended vagina. Sperm concentration was estimated photometrically, and semen was diluted rapidly in ultra-high temperature treated milk (UHT) or in extender E1 ((INRA82 $=1 / 2$ UHT milk and 1/2 solution containing sugars and salts) $+2 \%$ egg yolk (v/v)) (Palmer, 1984). Semen was used either freshly diluted or prepared according to pre-freezing or freeze-thaw procedures. The steps of the freezing technique (Vidament et al., 2000) were as follows: after initial dilution of semen in extender $\mathrm{E} 1$ at $50.10^{6}$ per $\mathrm{mL}$ and cooling at $22^{\circ} \mathrm{C}$ for 10 minutes, the semen was centrifuged $(600 \mathrm{x} \mathrm{g})$ for $10 \mathrm{~min}$ at ambient temperature (step 1). The resulting supernatant was discarded, the pellets resuspended in the freezing extender E2 (E1 + various \% CPA) to reach the concentration of $100 \times 10^{6}$ spermatozoa $/ \mathrm{ml}$ (step 2), and then cooled at $4^{\circ} \mathrm{C}$ for $1 \mathrm{~h} 15 \mathrm{~min}$ (step 3) before being packaged in straws $\left(0.5 \mathrm{ml}\right.$ ) and frozen (at $-60^{\circ} \mathrm{C} / \mathrm{min}$ down to $-140^{\circ} \mathrm{C}$ ), then plunged in liquid nitrogen (step 4). The different treatments are described precisely within each experiment (paragraph 2.5).

The CPAs, glycerol, DMF and EG were purchased from Sigma (Saint Quentin Fallavier, France). CPA concentrations are expressed below as final concentration in the diluted semen $(\mathrm{v} / \mathrm{v})$. If not specified, the CPA used in E2 was glycerol at $\sim 2.2 \%(\mathrm{v} / \mathrm{v})(2.5 \%$ in extender). In two trials, glutamine was added to E2 (final concentration $\sim 44$ mmol. $\mathrm{L}^{-1}$ ).

\subsection{Evaluation of sperm motility}

The sperm motility characteristics were measured by a computer-assisted motility analyzer (CASA) (HTM-IVOS, version 10.9, Hamilton Thorn Research, Beverly, MA, USA). Rapid motility was defined as the percentage of motile spermatozoa with average path velocity (VAP) higher than $40 \mu \mathrm{m} / \mathrm{sec}$. The parameter settings for this HTM-IVOS system were: 30 frames acquired at 60 frames per second, sorting on 16 frames/30 to define a track, minimum contrast 80, minimum cell size 4 pixels, lower VAP cut-off $20 \mu \mathrm{m} / \mathrm{s}$, VAP cut-off for progressive and rapid cells $40 \mu \mathrm{m} / \mathrm{s}$ and straightness cut-off for progressive cells 80 .

\subsection{Insemination and evaluation of fertility}

Follicular growth and ovulation were monitored daily by transrectal ultrasonography and mares and jennies were inseminated during oestrus, when they presented growing follicles of $33 \mathrm{~mm}$ (pony mares) or $35 \mathrm{~mm}$ (jennies and mares except ponies). If not specified, mares and jennies were inseminated just behind the cervix with $400 \times 10^{6}$ fresh or frozen total sperm per Artificial Insemination (AI) (4 ml), twice (24 and 48h) before ovulation, without further preparation of the semen. Pregnancy was diagnosed ultrasonographically 14 to 16 days after ovulation. Fertility was measured according to the per-cycle pregnancy rate (PC), defined as the total number of pregnancies divided by the total number of oestrus cycles bred. When frozen semen was used, only ejaculates with post-thaw rapid motility greater than $35 \%$ were selected for insemination. 


\subsection{Experimental procedures:}

2.5.1. Fertility of mares and jennies inseminated with cooled and frozen donkey semen Insemination with fresh semen diluted in milk

Breeding records from 2 donkey males (1 BdP and 1 Pyrénée breed) were analyzed retrospectively for their respective fertility in field mares $(n=49)$ and jennies $(n=13)$. These females were inseminated with $200 \times 10^{6}$ total sperm diluted in milk (10 ml total volume) and stored at $4^{\circ} \mathrm{C}$ for less than $8 \mathrm{~h}$ before insemination every other day, as long as they were in oestrus.

Insemination with semen frozen with glycerol Semen of 6 BdP donkeys was frozen in E2 containing 2.2\% glycerol and glutamine $(n=4)$ or without glutamine $(n=2)$. Field mares $(n=25)$ and jennies $(n=22)$ were inseminated with 800 $\mathrm{x} 10^{6}$ total sperm (16 straws, $8 \mathrm{ml}$ total volume) per AI before ovulation (usually twice, 24 and $48 \mathrm{~h}$ before ovulation) in different AI centres.

\subsubsection{Fertility of mares and jennies inseminated with intraspecies semen prepared with or without glycerol}

The aim of these experiments was to establish whether glycerol was the factor explaining the lower fertility observed in jennies: fresh stallion and donkey semen prepared according to prefreezing steps using different concentrations of glycerol was inseminated in mares and jennies, respectively.

\subsubsection{Horse species}

The effects of increasing glycerol concentrations (0, 2.2, 3.5, 4.8 and 6.2\%) were first measured on horse spermatozoa motility in vitro. Fresh semen of five pony stallions (x 1 ejaculate) was divided and prepared according to steps 1 to 3 with increasing glycerol concentrations in E2. At the end of step 3, semen was diluted at $20 \times 10^{6}$ spermatozoa $/ \mathrm{ml}$ with the extender containing the corresponding glycerol concentration. Velocity VAP and motility were evaluated after $48 \mathrm{~h}$ of storage at $4^{\circ} \mathrm{C}$.

Fresh semen of three pony stallions was prepared for in vivo study according to steps 1 to 3 with increasing glycerol concentrations $(0,2.2,3.5$ and $4.8 \%)$. At the end of step 3 , pony mares were inseminated once with $400 \times 10^{6}$ total sperm (4 ml total volume) $24 \mathrm{~h}$ before ovulation. Mares were randomly allocated to the different glycerol concentrations. The experiment was stopped when 5 cycles per stallion and per glycerol concentration group had been allocated. To monitor any possible post-AI uterine reaction due to glycerol, the uterus was scanned by ultrasonography 5 times (at Day 0, just before insemination, Day 1 (= Day of ovulation), Day 3, Day 5 and Day 8-10 after insemination). The following criteria were recorded: 1) measurements of uterus : maximum height of uterine body (on scans where the body was of regular pear shape (longitudinal section)), height and width of the base of each uterine horn (on scans where the base could just be distinguished from the body and was of regular elliptical shape), 2 ) uterus score $(0=$ no endometrial folds, $2=$ small folds, $3=$ marked folds and 4 = prominent folds with oedema), 3 ) presence of liquid in the uterine body. The surfaces of the base of each horn were then calculated and pooled. These examinations were performed during the insemination cycles with semen from the first two stallions.

\subsubsection{Donkey species}

Fresh semen from two BdP donkeys was divided and prepared according to the following four treatments. The semen was 1) diluted in milk at $35^{\circ} \mathrm{C}$ (treatment 1 ), 2) diluted in milk at $35^{\circ} \mathrm{C}$ 
and then centrifuged; the pellet was resuspended in milk at $22^{\circ} \mathrm{C}$ and then cooled to $4^{\circ} \mathrm{C}$ (treatment 2), 3) diluted in $\mathrm{E} 1$ at $35^{\circ} \mathrm{C}$ and centrifuged; the pellet was resuspended in $\mathrm{E} 1$ and then cooled to $4^{\circ} \mathrm{C}$ (treatment 3) or 4) diluted in $\mathrm{E} 1$ at $35^{\circ} \mathrm{C}$ and centrifuged; the pellet was resuspended in E2 containing glycerol and then cooled (treatment 4). Treatment 4 represented steps $1-3$ of the prefreezing procedure. In treatment $1,400 \times 10^{6}$ sperm were diluted in $10 \mathrm{ml}$. In treatments 2-4, $460 \times 10^{6}$ sperm were diluted in $10 \mathrm{ml}$ and centrifuged, and the pellet $(1 \mathrm{ml})$ was diluted with the extender (total $4 \mathrm{ml}$ ). Seven undefined breed jennies (x 2 or 3 cycles) and $6 \mathrm{BdP}$ jennies (x 2 cycles) were inseminated immediately after the end of preparation of semen with $400 \times 10^{6}$ total sperm every other day until ovulation.

2.5.3. Fertility of jennies inseminated with cooled donkey semen prepared with or without different CPAs

Concentrations of alternative CPAs were chosen for donkey semen according to findings obtained for stallion semen in our laboratory. A dimethylformamide (DMF) concentration of around $2 \%$ was chosen according to previous results of motility and fertility (Vidament et al., 2002) and to other unpublished data. For ethylene glycol (EG), a preliminary in vitro study evaluated the effects of increasing concentrations $(0,1.4,1.9$, and 3.8\%) on spermatozoa motility: semen of five stallions (x 1 ejaculate) was prepared according to steps 1 to 3 and cooled to $4^{\circ} \mathrm{C}$. After $1 \mathrm{~h} 15 \mathrm{~min}$, semen was either frozen or kept unfrozen, and then diluted at $20 \times 10^{6}$ spermatozoa/ml with the extender containing the previous EG concentration and stored at $4^{\circ} \mathrm{C}$ for $48 \mathrm{~h}$.

In an in vivo study, fresh semen from three BdP donkeys was prepared according to steps 1 to 3 , as described for treatment 4 in the above trial (paragraph 2.5.2.2.). The final concentration of CPAs in E2 were: $0 \%$ or $1.9 \%$ glycerol $(0.26 \mathrm{M})$, $2 \%$ DMF $(0.26 \mathrm{M})$ or $1.3 \%$ EG $(0.26$ $\mathrm{M})$. Jennies (7 undefined breed jennies $\mathrm{x} 4$ cycles and $6 \mathrm{BdP}$ jennies $\mathrm{x} 3$ cycles) were then inseminated with fresh semen at $4^{\circ} \mathrm{C}$ every day until ovulation.

2.5.4. Attempts to improve the fertility of jennies inseminated with frozen donkey semen 2.4.4.1. Removal of glycerol during the thawing process (post-thaw dilution or washing) Semen of five BdP donkeys was frozen in E2 containing glycerol and glutamine (3 donkeys) or without glutamine (2 donkeys). After thawing 8 straws ( $400 \times 10^{6}$ sperm), $10 \mathrm{ml}$ of milk were added drop by drop to the semen tube (total $14 \mathrm{ml}$ ). AI was performed in BdP jennies (11 BdP jennies $x 1$ or 2 cycles).

Semen of two other donkeys (1 BdP and 1 Grand Noir Berry) was frozen in E2 containing glycerol. After thawing, the semen was inseminated either without further dilution (8 straws) (Control), or after washing in milk ( 9 straws) as follows. The contents of the 9 straws were divided into two centrifugation tubes. Eleven $\mathrm{ml}$ of milk at $35^{\circ} \mathrm{C}$ were added drop by drop to each tube and the pellet $(1 \mathrm{ml})$ was resuspended in $1 \mathrm{ml}$ of milk at $22^{\circ} \mathrm{C}$ after centrifugation. The contents of both tubes were gathered $(4 \mathrm{ml})$ and used for insemination. Four hundred million total sperm diluted in $4 \mathrm{ml}$ were inseminated (6 undefined breed jennies $\mathrm{x} 2$ or 3 cycles).

\subsubsection{Substitution of glycerol by DMF}

Ejaculates from two BdP donkeys ( $\mathrm{n}=3$ for male 1 and $\mathrm{n}=6$ for male 2) were divided into two parts and frozen with $2.1 \%$ glycerol or with $2.2 \%$ DMF. Ejaculates with post-thaw rapid motility of 35\% or more with glycerol and DMF were used for insemination (7 undefined breed jennies x 3 cycles and 12 BdP jennies x 1 or 2 cycles).

\subsection{Statistical analysis}


The Chi-square test was used to compare the percentages (PC) in the field trials. In experimental fertility trials, differences between percentages (PC) were tested with linear categorical data analysis, considering effects of treatment and male sand treatment $\mathrm{x}$ male interaction (CATMOD, SAS Institute Inc., Cary, NC, USA). If the treatment x male interaction was not significant, the model was considered as valid. The software calculated then weighed least squares estimates of the mean percentage on overall data (intercept) and of all effects and their significance. In the fertility trial with fresh donkey semen prepared with different CPAs, one donkey ("Leo") with hemospermia was replaced by another ("Mar”) during the trial. A smaller number of cycles per treatment was allocated to these 2 donkeys, and the statistical analysis was therefore performed after removing the result of treatment 1 with donkey "Mar" (1 cycle) because the model was not valid if this result was retained. General differences between means of sperm characteristics were tested by a factorial analysis for balanced or unbalanced data (GLM procedure of SAS, SAS Institute Inc., Cary, NC, USA) considering the effects of sperm treatment, male and ejaculate within male (if more than one ejaculate per male was being considered).

\section{Results}

\subsection{Fertility of mares and jennies inseminated with cooled and frozen donkey semen}

The results reported on Table 1 clearly show that per-cycle pregnancy rates (PC) obtained with jennies and mares were similar (45 \%) when the females of the two species were inseminated with donkey semen diluted in milk and used unfrozen.

The results were very different with frozen donkey semen. The PC obtained with jennies was very low (11\%). However, the PC obtained with mares were 3-4 times higher $(\mathrm{P}<0.01)$, although the post-thaw motility was the same for the sperm used to inseminate mares and jennies (mean: $56 \%$ rapid motility).

\subsection{Fertility of mares and jennies inseminated with intraspecies semen prepared with or} without glycerol

\section{Horse species}

The addition of glycerol to unfrozen stallion semen had a deleterious effect on motility and PC (Tables 2 and 3). In fertility study, the highest amount tested (4.8\% glycerol) was the most deleterious $(\mathrm{P}<0.0001)$. The lower concentrations $(2.2$ and $3.5 \%$ glycerol) gave intermediate results. The toxicity of glycerol could not be related to any possible strong inflammation of the uterus as measured by uterine scores, height of uterine body (data not shown) and uterine horn size (surfaces) (Table 4): all of these uterine parameters decreased rapidly with the interval between insemination and measurement, but there was no relationship with the glycerol concentration added at the time of insemination. In addition, liquid in the uterus was very rare (8 times on 200 examinations : 1 time / 40 at Day 0, 6 times / 40 at Day 1 (1 or 2 times in each glycerol concentration / 10 cycles) and 1 time / 40 at Day 3).

\section{Donkey species}

The effects of the successive steps of the pre-freezing procedure of donkey semen on the PC measured after insemination of jennies are reported on Table 5 . The successive steps gradually decreased PC $(\mathrm{P}<0.0001)$. However, the addition of $2.2 \%$ glycerol induced the most 
dramatic fall as PC decreased from $64 \%$ before addition of the cryoprotectant to $0 \%$ after addition.

3.3. Fertility of jennies inseminated with cooled donkey semen prepared with or without different CPAs

In the preliminary in vitro study evaluating the effects of increasing EG concentrations $(0,1.4$, 1.9 , and $3.8 \%$ ) on stallion spermatozoon motility, rapid motility of unfrozen sperm was $84^{\mathrm{A}}$, $81^{\mathrm{AB}}, 81^{\mathrm{AB}}$ and $77 \%^{\mathrm{B}}$, respectively. For frozen semen, rapid motility was $22^{\mathrm{B}}, 33^{\mathrm{AB}}, 40^{\mathrm{A}}$ and $47 \%{ }^{\mathrm{A}}$, respectively. Different superscript letters denote differences between concentrations $(\mathrm{P}<0.05)$.

Finally all CPAs (glycerol, DMF, EG) were used at the same molarity $(0.26 \mathrm{M})$ in the in vivo study. When glycerol was replaced by DMF or EG during the prefreezing procedure, the PC obtained with jennies was less dramatically affected (Table 6) $(\mathrm{P}<0.0001)$. In addition, DMF did not seem to be toxic because the PC obtained with this cryoprotectant was similar to that obtained without the addition of CPA (78 vs $81 \%$ ). Moreover, these PCs were significantly higher than the adjusted mean for all treatments $(54 \%)(\mathrm{P}<0.03)$. EG tended to be less toxic than glycerol although the PC results obtained with this CPA were intermediate (45\%).

\subsection{Attempts to improve the fertility of jennies inseminated with frozen donkey semen}

Removal of glycerol during thawing process (post-thaw dilution or washing).

No pregnancies occurred in jennies when frozen donkey semen was diluted in milk without washing at thawing (Table 7). The same occurred after additional dilution of frozen-thawed semen in milk to reduce the proportion of glycerol. When frozen semen was washed in milk after thawing, one pregnancy occurred out of 8 cycles. However, there were no significant differences between treatments.

Substitution of glycerol by DMF.

The motility characteristics of frozen-thawed donkey semen were not significantly different when similar concentrations of glycerol or DMF were used: rapid motility was $54 \%$ and $47 \%$ (pooled S.E.M = 2) and VAP was 99 and $101 \mu \mathrm{m} / \mathrm{sec}$ (pooled S.E.M.= 3), respectively. PCs were low and not significantly different when semen was frozen in the presence of glycerol or DMF (Table 8) $(\mathrm{P}=0.08)$.

\section{Discussion}

Semen cryopreservation is now successfully used in $80-85 \%$ of the stallions of light breeds in France (Vidament, 2005). The situation is very different for the donkey species, despite the close phylogeny with the stallion. Semen cryopreservation is not successful in the donkey species although donkeys of different breeds are often reported to produce large quantities of high quality semen (Ferreira et al., 1992, Santos et al., 1995, Gastal et al., 1997, Trimeche et al, 1998, Miro et al. 2005). This situation, which is dramatic for the maintenance of genetic diversity, leads to questions regarding the freezability of donkey spermatozoa, the ability of jennies to be inseminated with frozen semen, and consequently the validity/quality of the current methods of cryopreservation and /or insemination. The present study sheds new light on the effects of cryopreservation procedures on donkey and stallion semen, and it provides information regarding the fertility obtained after AI of jennies and mares with frozen or unfrozen semen, with or without the CPA glycerol. 
We showed in this study that fertility is similar when mares and jennies are inseminated with cooled donkey semen diluted in extender without CPA, thus complementing previous results obtained on sperm motility (Santos et al., 1995, Cotorello et al. 2002, Seres et al., 2002) and on fertility obtained after insemination of mares for mule production (Glatzel et al., 1981, Ferreira et al., 1992). However, no fertility results are available in the literature regarding fresh donkey semen inseminated in jennies, although this seems to be the practice in some places and in some countries. According to previous studies, the motility of frozen-thawed semen is often very high (Trimeche et al. 1996, 1998, Oliveira et al. 2006). However, despite this high motility after freeze-thawing, we demonstrated that the resulting fertility was very low in jennies but clearly higher in mares. The low fertility obtained with frozen donkey semen has already been documented by other authors using different extenders and amounts of cryoprotectant or combinations of cryoprotectants. Trimeche et al. (1998) reported no pregnancies in 17 cycles for jennies inseminated with donkey semen frozen in an extender containing $4 \%$ glycerol, $10 \%$ quail egg yolk and $80 \mathrm{mM}$ glutamine (final glycerol concentration $\sim 3 \%$ ), then thawed and inseminated without dilution. In a preliminary report, Oliveira et al. (2006) obtained no pregnancies in jennies (53 cycles) inseminated with semen of one donkey male, frozen with different combinations of glycerol, DMF, DMA or DMSO (total concentration: 2 to 5\%). Moreover, they obtained 4 pregnancies in 10 cycles in mares inseminated with semen of this donkey, frozen with one combination (3\% glycerol and 2\% DMF).

The higher fertility obtained after insemination of mares with frozen donkey semen in the present study (50 cycles) raises numerous questions. One hypothesis is that the potential toxicity of glycerol on spermatozoa or on the female genital tract may be more enhanced in jennies than in mares. All our intra-species results with donkey semen were in agreement: when $\sim 2 \%$ glycerol was added to semen, the resulting fertility was nil or very low, both with fresh and frozen semen. In contrast, fertility results obtained with mares inseminated with frozen equine semen containing 2-2.2\% glycerol are very satisfactory (Vidament 2005). However, even in the equine species, we demonstrated in the present study a significant deleterious effect of the highest concentration of glycerol (4.8\%) on fertility. These results are in agreement with the decline in motility observed in fresh semen (Table 2) and with the results published by Ball and Vo (2001) that showed deleterious effects on motility and acrosome integrity of fresh equine sperm diluted in extender containing increasing concentrations of glycerol. Such effects could explain the low fertility results previously obtained with stallion semen extended with high glycerol concentrations (4 to 7\%: Pickett et al., 1975, Demick et al., 1976, Bedford et al., 1995).

Glycerol toxicity has also been demonstrated on spermatozoa of other species including bulls (at 10\%), rams (at 7-10\%) and boars (at 8\%) (Graham et al., 1978, Watson 1979, Buhr et al., 2001). Taken together, the present results show that donkey and stallion spermatozoa may be damaged by glycerol, but the toxic effect of glycerol is more obvious at higher concentrations for stallion than for donkey sperm. The glycerol concentration for maximum post-thaw motility is difficult to determine in horses, and could be influenced by the composition of the extender. The optimal concentration would represent a compromise between the maximal post-thaw sperm characteristics and negative effects on fertility. The recommended final glycerol concentration for both motility and fertility could be 2.5 to $3.5 \%$ for equine species (see review in Vidament 2005). 
The second hypothesis to explain the deleterious effect of semen frozen with glycerol on the fertility of jennies but not of mares could be a direct effect of glycerol on the female genital tract. It is commonly accepted in equines that insemination with frozen semen leads to greater post-AI fluid accumulation than insemination with fresh semen or natural service. We therefore explored the effects of increased glycerol concentrations in the insemination dose on the mare uterus. Uterus score, body size and horn surfaces decreased from Day 0 to Day 3 post-insemination due to the ovarian cycle, but no changes related to glycerol concentration were observed. This was also the case for fluid accumulation. These simple techniques of observation of uterine inflammation were compatible with the beginning of pregnancies. These results are in agreement with recent studies in which frozen semen was reported not to induce more uterine inflammation and fluid accumulation than fresh semen or natural service in mares (Watson et al., 2001, Barbacini et al., 2003, Card et al., 2004, Katila et al. 2005). The contraceptive effect of glycerol has mostly been documented in bird species, especially in chickens and turkeys, although glycerol is one of the most successful cryoprotectants for spermatozoa in these species (reviewed by Hammerstedt and Graham 1992, Tselutin et al, 1999). The contraceptive effect is noticeable with intra-vaginal insemination but fertility can be restored by removing glycerol to below $0.1 \mathrm{M}$ during the thawing process (by high dilution or by washing with centrifugation). Glycerol is contraceptive if it is deposited between 5 min before and 10 min after insemination in the vagina, but insemination in higher parts of the female tract (oviduct) does not reduce fertility (Hammerstedt and Graham, 1992). Glycerol can also affect the female tract by changes in osmolarity, uterine liquid, ciliary movements, sperm storage and release (Hammerstedt and Graham, 1992) and composition of uterine or vaginal liquid in birds (Delee et al, 1991). The situation is very different in horse and donkey species because of specific physiological features (e.g. sperm storage tubules in birds at the utero-vaginal junction, not in mares and jennies...) and because insemination is intra-uterine. Possible interaction between glycerol and milk extender in jennies genital tract may also not be excluded. However many of the potential effects of glycerol on the donkey female genital tract remain to be explored.

Whatever the explanation, it is difficult to suggest a decrease in the concentration of glycerol for spermatozoa of donkey species because $2 \%$ is already quite low to obtain a cryoprotectant effect. Two strategies were therefore developed to limit the effect of glycerol and to improve the fertility of frozen semen in donkey species, i.e. partial post-thaw removal of glycerol and pre-freezing replacement of glycerol by DMF. However, the simple dilution or washing (high dilution/centrifugation/re-dilution) of frozen donkey semen was not sufficient to improve fertility in jennies. In the first procedure, the concentration of the extender components (glycerol, egg yolk.....) delivered to the jennies was halved. In the second procedure, the extender components delivered to the jennies was divided by ten and their concentrations in the AI dose were very weak. However, our results did not agree with those of Trimeche et al. (1998) who obtained 8 pregnancies in 21 cycles when donkey semen frozen in an extender containing $4 \%$ glycerol was diluted after thawing with the same volume of the base extender without glycerol, added sequentially. These results have not been confirmed to date.

On the other hand, when glycerol was replaced by DMF and EG for donkey semen, the fertility of fresh semen was similar to that of fresh semen without CPA, showing that DMF and EG are less toxic than glycerol. However, the fertility of jennies after insemination of donkey spermatozoa frozen with DMF was still very low, despite satisfactory post-thaw motility (Table 8). This discrepancy between good motility and low fertility obtained with 
frozen semen in donkey species has also recently been described with semen frozen with different combinations of CPA (Oliveira et al., 2006), indicating that motility is a very poor predictor of fertility, in this case. The different strategies to limit the effects of glycerol were thus unsuccessful.

In addition to the negative effect of glycerol, there was certainly a profound effect of the semen freezing process itself, small changes in spermatozoa being enhanced in jennies compared to mares. Among the many potential factors involved, the interactions between semen and the female genital tract (uterus, oviduct, oocyte) are so numerous and complex, that a single dysfunction may result in reduced fertility. It would therefore be important to explore 1) spermatozoon functions known to be important during their transit in the female tract such as capacitation, membrane stability and acrosome reaction, 2) the interactions between the genital tract and spermatozoa (uterus transport, oviduct storage), 3) seminal plasma composition before and after freezing, 4) the effects of freezing on the components of the freezing extender. Some of these aspects are currently under study in our laboratory. Deep-horn insemination in jennies near the oviductal papilla could be an approach to rise the number of spermatozoa near the site of storage.

In conclusion, the present study clearly showed that the ability of jennies to conceive after AI with frozen donkey semen is lower than that of mares. The greater efficacy of inter-species crossing compared to intra-species fertilization raised several questions, one of which being the CPA used, i.e. glycerol. However, we also demonstrated that removal of glycerol on thawing does not restore fertility and that glycerol may affect the motility and fertility of donkey and stallion spermatozoa as early as the prefreezing process. This effect was concentration-dependent but the toxic concentration for donkey spermatozoa was almost half that of stallion spermatozoa. Whether this greater sensitivity of donkey spermatozoa to glycerol was responsible for the low success of semen cryopreservation in jennies is not so obvious because replacement of glycerol by DMF, that seemed less toxic to donkey spermatozoa, was not much more effective. Taken together, these results show that further studies should focus on the sensitivity of donkey sperm to cryopreservation and on the suitability of the jenny's oviduct to storing frozen-thawed semen.

\section{Acknowledgements}

The authors thank J-M. Yvon (INRA Nouzilly) for technical help in all circumstances, the staff of Les Haras Nationaux, Saintes (among them T. Clausse, V. Cinqualbre for access to the donkeys and organisational help, C. Berland, R. Eluen , C. Foucher for technical help in the donkeys centre of La Tillauderie, 17470 Dampierre), B. Lalanne for providing additional jennies, C. Leroy and G. Marionneau (Les Haras Nationaux, Hennebont) for the freezing of donkey semen in the first trial, C. de Lartigue (Les Haras Nationaux, Tarbes) for access to retrospective data on fresh semen insemination in donkeys, F. Clément (Les Haras Nationaux) and B. Biteau (Parc Régional du Marais Poitevin) for organisational help, the staff of the experimental equine herd in INRA Nouzilly (among them G. Duchamp and B. Bruneau for organisational help during donkey semen freezing in Nouzilly and technical help during the horse fertility experiment), N. Montaigne for help during the horse fertility experiment, D. Raine for english revision of the manuscript, P. Ecot and J.P. Brillard for constructive discussions about the experimental protocols. 


\section{References}

Alvarenga, M.A., Papa, F.O., Landim-Alvarenga, F.C., Medeiros, A.S.L., 2005. Utilization of amides as cryoprotectors for freezing stallion semen. Anim. Reprod. Sci. 89, 105-113.

Alvarez, A. L., Serres, C., Torres, P., Crespo, F., Mateos, E., Gomez-Cuetara, C., 2006. Effect of cholesterol-loaded cyclodextrin on the cryopreservation of donkey spermatozoa, Margaret J. Evans (Ed.), Equine Reproduction IX. Anim. Reprod. Sci. 94, 89-91.

Ball, B.A., Vo, A., 2001. Osmotic tolerance of equine spermatozoa and the effects of soluble cryoprotectants on equine sperm motility, viability and mitochondrial membrane potential. J. Androl. 72, 1061-1069.

Barbacini, S, Necchi, D, Zavaglia, G, Squires, E.L., 2003. Retrospective study on the incidence of postinsemination uterine fluid in mares inseminated with frozen/thawed semen. J. Equine Vet. Sci. 23, 493496.

Bedford, S.J., Jasko, D.J., Graham, J.K., Amann, R.P., Squires, E.L., Pickett, B.W., 1995. Effect of seminal extenders containing egg yolk and glycerol on motion characteristics and fertility of stallion spermatozoa. Theriogenology 43, 955-967.

Buhr, M.M., Fiser, P., Bailey, J.L., Curtis, E.F., 2001. Cryopreservation in different concentrations of glycerol alters boar sperm and their membranes. J. Androl. 22, 961-969.

Card, C., Carley, S., Green, J., Chirino-Trejo, M., 2004. Endometrial cytology in mares bred with frozen semen. In: Proceedings of the 50th convention of the AAEP, Denver, Colorado, USA, 4-8 December, Publisher: American Association of Equine Practitioners, Lexington KY, pp 505-509.

Chalah, T., Seigneurin, F., Blesbois, E., Brillard, J.P., 1999. In vitro comparison of fowl sperm viability in ejaculates frozen by three different techniques and relationship with subsequent fertility in vivo. Cryobiology 39, 185-191.

Cottorello, A.C.P., Amancio, R.C., Henry, M., Borge, I., 2002. Effect of storage temperature and extenders on "in vitro” activity of donkey spermatozoa, Margaret J. Evans (Ed.), Equine Reproduction VIII. Theriogenology 58, 325-328.

Delee, J.A., Harris, G.C. Jr, Macy, L.B., 1991. Research note: the in vitro responses of vaginal tissue and chicken spermatozoa to glycerol. Poult. Sci. 70, 1441-1443.

Demick, D.S., Voss, J.L., Pickett, B.W., 1976. Effect of cooling, storage, glycerolization and spermatozoal numbers on equine fertility. J. Anim. Sci. 43, 633-637.

Ferreira, M.F.L., Henry, M., 1992. Effect of cooling rate and seminal extenders on sperm longevity and fertility in donkeys. In: Proceedings of $12^{\text {th }}$ International Congress on Animal Reproduction, The Hague, 3, pp. 14061408.

Gastal, M. O., Henry, M., Beker, A. R.; Gastal, E. L., 1997. Effect of ejaculation frequency and season on donkey jack semen. Theriogenology 47, 627-638.

Glatzel, P., El-Houssain, K., Tibary, A., 1981. Pferde- und Eselhengste der marokkanischen Landespferde- und Maultierzucht. Erste Ergebnisse aus dem Einsatz von Flussig- und Gefriersamen fur die Maultierproduktion. Berl. Munch. Tierarztl. Wochenschr. 94, 445-448.

Graham, E.F., Crabo, B.G., Pace, M.M., 1978. Current status of semen preservation in the ram, boar and stallion. J. Anim. Sci. Supp. 41, 80-119.

Hammerstedt, R.H., Graham, J.K., 1992. Cryopreservation of poultry sperm : the enigma of glycerol. Cryobiology 29, 26-38.

Katila, T., 2005. Effect of the inseminate and the site of insemination on the uterus and pregnancy rates of mares. Anim. Reprod. Sci. 89, 31-38.

Mantovani, R., Rota, A., Falomo, M.E., Bailoni, L., Vincenti, L., 2002. Comparison between glycerol and ethylene glycol for the cryopreservation of equine spermatozoa : semen quality assessment with standard analyses and with the hypoosmotic swelling test. Reprod. Nutr. Dev. 42, 217-226.

Miro, J., Lobo, V., Quintero-Moreno, A., Medrano, A., Pena, A., Rigau, T., 2005. Sperm motility patterns and metabolism in Catalonian donkey semen. Theriogenology 63, 1706-1716.

Oliveira, J.V., Alvarenga, M.A., Melo, C.M., Macedo, L.M., Dell’ Aqua Jr., J.A., Papa, F.O., 2006. Effect of cryoprotectant on donkey semen freezability and fertility. Margaret J. Evans (Ed.), Equine Reproduction IX. Anim. Reprod. Sci. 94, 82-84.

Pace, M.M., Sullivan, J.J., 1975. Effect of timing of insemination, numbers of spermatozoa and extender components on the pregnancy rate in mares inseminated with frozen stallion semen. I.W. Rowland, W.R. Allen, P.D. Rossdale (Eds), Equine Reproduction. J. Reprod. Fert. Suppl 23, 115-121.

Palmer, E., 1984. Factors affecting stallion semen survival and fertility. In: Proceedings 10th International Congress on Animal Reproduction and Artificial Insemination, Urbana, vol 3, Abstract 377.

Piao, S., Wang, Y., 1988. A study of the technique of freezing concentrated semen of horses (donkeys) and the aspect of insemination. In: Proceedings 11th International Congress on Animal Reproduction and Artificial Insemination, Dublin, vol 3, Abstract 286. 
Pickett, B.W., Sullivan, J.J., Byers, W.W., Pace, M.M., Remmenga, E.E., 1975. Effect of centrifugation and seminal plasma on motility and fertility of stallion and bull spermatozoa. Fertil. Steril. 26, 167-174.

Santos, G.F., Henry, M., Sampaio, I.B.M., Gastal, E.L., 1995. Effect of cooling system and rate of cooling on sperm quality of donkey semen preserved at $5^{\circ} \mathrm{C}$. Dan C. Sharp and Fuller W. Bazer (Eds.), Equine Reproduction VI. Biol. Reprod. Mono 1, 761-767.

Serres, C., Rodriguez, A., Alvarez, A.L., Santiago, I., Gabriel, J., Gomez-Cuétara, C., Mateos, E., 2002. Effect of centrifugation and temperature on the motility and plasma membrane integrity of Zamorano-Leonés donkey semen, Margaret J. Evans (Ed.), Equine Reproduction VIII. Theriogenology 58, 329-332.

Silva, S. S., Henry, M., Nunes, S. A., Mello, S.L.V., 1997. Influencia do sistema de envasamento sobre a qualidade espermatica de jumentos (Equus asinus) avaliada "in vitro" pos-descongelacao (Effect of packaging on the quality of frozen donkey semen, evaluated in vitro after thawing). Revista Brasileira de Reproducao Animal 21, 140-146.

Squires, E.L., Keith, S.L., Graham, J.K., 2004. Evaluation of alternative cryoprotectants for preserving stallion spermatozoa. Theriogenology 62, 1056-1065.

Trimeche, A., Renard, P., Le Lannou, D., Barrière, P., Tainturier, D., 1996. Improvement of motility of post-thaw poitou jackass sperm using glutamine. Theriogenology 45, 1015-1027.

Trimeche, A., Renard, P., Tainturier, D., 1998. A procedure for poitou jackass sperm cryopreservation. Theriogenology 50, 793-806.

Tselutin, K, Seigneurin, F, Blesbois, E, 1999. Comparison of cryoprotectants and methods of cryopreservation of fowl spermatozoa, Poult. Sci. 78, 586-590.

Vidament, M., 2005. French field results (1985-2005) on factors affecting fertility of frozen stallion semen, Edward Squires (Ed.), Proceedings of the $4^{\text {th }}$ International Symposium on Stallion Reproduction. Anim. Reprod. Sci. 89, 115-136.

Vidament, M., Daire, C., Yvon, J.M., Doligez, P., Bruneau, B., Magistrini, M., Ecot, P., 2002. Motility and fertility of stallion semen frozen with glycerol and/or dimethyl formamide, Margaret J. Evans (Ed.), Equine Reproduction VIII. Theriogenology 58, 249-251.

Vidament, M., Ecot P., Noue, P., Bourgeois, C., Magistrini, M., Palmer, E., 2000. Centrifugation and addition of glycerol at $22^{\circ} \mathrm{C}$ instead of $4^{\circ} \mathrm{C}$ improve post-thaw motility and fertility of stallion spermatozoa. Theriogenology 54, 907-919.

Watson, E.D., Barbacini, S., Berrocal, B., Sheerin, O., Marchi, V., Zavaglia, G., Necchi, D., 2001. Effect of insemination time of frozen semen on incidence of uterine fluid in mares. Theriogenology 56, 123-131.

Watson, PF., 1979. The preservation of semen in mammals. In: Fin, G.C., (Ed.), Oxford reviews of reproductive biology, Oxford University Press Publisher, London, pp 283-350. 
Table 1: Per-cycle pregnancy rate after insemination of jennies (=donkey females) and mares (=horse females) with donkey semen either cooled to $4^{\circ} \mathrm{C}$ or frozen

\begin{tabular}{|c|c|c|}
\hline Female species & $\begin{array}{c}\text { Fresh semen } \\
\text { diluted in milk and } \\
\text { cooled ( } 2 \text { males) }\end{array}$ & $\begin{array}{c}\text { Frozen semen } \\
{\text { with } 2.2 \% \text { glycerol }^{1}}^{1} \\
(6 \text { males })\end{array}$ \\
\hline Jennies & $9 / 20(45 \%)$ & $4 / 38(11 \%)^{A}$ \\
\hline Mares & $33 / 73(45 \%)$ & $18 / 50(36 \%)^{\text {B }}$ \\
\hline
\end{tabular}

Table 2: Motility of stallion semen centrifuged, diluted in extender supplemented with increasing concentrations of glycerol and stored for $48 \mathrm{~h}$ at $4^{\circ} \mathrm{C}$.

\begin{tabular}{|c|c|c|c|c|c|c|}
\hline $\begin{array}{c}\text { Glycerol } \\
\left(\text { final } \%^{1} \text { ) }\right.\end{array}$ & 0 & 2.2 & 3.5 & 4.8 & 6.2 & $\begin{array}{l}\text { Pooled } \\
\text { S.E.M. }\end{array}$ \\
\hline Rapid motility (\%) & $77^{\mathrm{A}}$ & $74^{\mathrm{A}}$ & $70^{\mathrm{AB}}$ & $63^{\mathrm{B}}$ & $54^{\mathrm{C}}$ & 4 \\
\hline $\operatorname{VAP}(\mu \mathrm{m} / \mathrm{sec})^{2}$ & $99^{\mathrm{A}}$ & $87^{\mathrm{B}}$ & $82^{\mathrm{B}}$ & $75^{c}$ & $67^{\mathrm{D}}$ & 3 \\
\hline
\end{tabular}

Table 3: Per-cycle pregnancy rate (PC) after insemination of mares with cooled semen of 3 stallions (diluted, centrifuged, diluted in extender supplemented with increasing concentrations of glycerol and cooled to $4^{\circ} \mathrm{C}$ for 1 hour).

\begin{tabular}{|c|c|c|c|c|c|c|}
\hline $\begin{array}{r}\text { Glycerol } \\
\left(\text { final } \%^{1} \text { ) }\right.\end{array}$ & Male 1 & Male 2 & Male 3 & Total & $\begin{array}{c}\text { Observed } \\
\text { PC }\end{array}$ & $\begin{array}{c}\text { Estimated } \\
\text { PC }^{2}\end{array}$ \\
\hline $0 \%$ & $4 / 5$ & $5 / 5$ & $4 / 5$ & $13 / 15$ & $87 \%$ & 88 \%*** \\
\hline $2.2 \%$ & $2 / 5$ & $3 / 5$ & $3 / 5$ & $8 / 15$ & $53 \%$ & $53 \%$ \\
\hline $3.5 \%$ & $1 / 5$ & $3 / 5$ & $4 / 5$ & $8 / 15$ & $53 \%$ & $54 \%$ \\
\hline $4.8 \%$ & $1 / 5$ & $1 / 5$ & $0 / 5$ & $2 / 15$ & $13 \%$ & $3 \% * * *$ \\
\hline
\end{tabular}


Table 4 : Size of uterus of mares before and after insemination with cooled stallion semen (diluted, centrifuged, diluted in extender supplemented with increasing concentrations of glycerol and cooled to $4^{\circ} \mathrm{C}$ for 1 hour).

\begin{tabular}{ccccccc}
\hline Glycerol $\left(\right.$ final $\%^{1}$ ) & Day 0 (before AI) & Day 1 (OV) & Day 3 & Day 5 & Day 8-10 & Total \\
\hline $0 \%$ & 19 & 16 & 16 & 15 & 14 & 16 \\
$2.2 \%$ & 19 & 18 & 14 & 14 & 13 & 15 \\
$3.5 \%$ & 18 & 16 & 14 & 14 & 15 & 15 \\
$4.8 \%$ & 18 & 18 & 15 & 16 & 13 & 16 \\
Total & $18^{\mathrm{A}}$ & $17^{\mathrm{B}}$ & $15^{\mathrm{B}}$ & $15^{\mathrm{B}}$ & $14^{\mathrm{B}}$ \\
\hline $1 \mathrm{v} / \mathrm{v}$ & $\mathrm{AI}$ insemination & \multicolumn{7}{c}{ OV: ovulation }
\end{tabular}

The size of uterus was evaluated ultrasonographically by measuring the sum of the transverse sections $\left(\mathrm{cm}^{2}\right)$ of the bases of both uterine horns before insemination at Day 0 (one day before ovulation) and 3, 5, 8-10 days after. Values are those observed in 10 mares per day per glycerol concentration (pooled SEM : 0.9).

${ }^{\mathrm{A}, \mathrm{B}}$ Different letters within a row denote significant differences $(\mathrm{P}<0.05)$.

Table 5: Per-cycle pregnancy rate (PC) after insemination of jennies with semen of 2 donkey males (diluted in milk and inseminated immediately or prepared with different steps of the pre-freezing procedure)

\begin{tabular}{|c|c|c|c|c|c|c|}
\hline Semen treatment & $\begin{array}{c}\text { Glycerol } \\
\left(\text { final } \%{ }^{1} \text { ) }\right.\end{array}$ & $\begin{array}{c}\text { Male } 1 \\
\text { Her }\end{array}$ & $\begin{array}{c}\text { Male } 2 \\
\text { Lor }\end{array}$ & Total & $\begin{array}{c}\text { Observed } \\
\text { PC (\%) }\end{array}$ & $\begin{array}{c}\text { Estimated } \\
\text { PC }^{2}(\%)\end{array}$ \\
\hline 1: Milk & 0 & $3 / 3$ & $3 / 4$ & $6 / 7$ & $86 \%$ & $99 \% * * *$ \\
\hline 2: Milk/Centri /Milk/4º & 0 & $4 / 5$ & $3 / 4$ & $7 / 9$ & $78 \%$ & $78 \%$ \\
\hline 3: E1 $/$ Centri $/ \mathrm{E} 1 \quad / 4^{\circ} \mathrm{C}$ & 0 & $2 / 4$ & $3 / 4$ & $5 / 8$ & $63 \%$ & $64 \%$ \\
\hline 4: E1 /Centri $/ \mathrm{E} 1+2.2 \% \mathrm{G} / 4^{\circ} \mathrm{C}$ & 2.2 & $0 / 4$ & $0 / 4$ & $0 / 8$ & $0 \%$ & $0 \% * * *$ \\
\hline
\end{tabular}


Table 6: Per-cycle pregnancy rate (PC) after insemination of jennies with cooled semen of 3 donkey males (diluted, centrifuged, diluted in extender supplemented with different cryoprotectants and cooled to $4^{\circ} \mathrm{C}$ for 1 hour).

\begin{tabular}{|c|c|c|c|c|c|c|}
\hline $\begin{array}{l}\text { Cryoprotectant } \\
\left(\text { final } \%^{1} \text { ) }\right.\end{array}$ & $\begin{array}{l}\text { Male } 1 \\
\text { Leo }^{\text {h }}\end{array}$ & $\begin{array}{c}\text { Male } 2 \\
\text { Mar }\end{array}$ & $\begin{array}{c}\text { Male } 3 \\
\text { Lor }\end{array}$ & Total & $\begin{array}{c}\text { Observed } \\
\text { PC } \\
\end{array}$ & $\begin{array}{c}\text { Estimated } \\
\text { PC }^{2} \\
\end{array}$ \\
\hline $0 \%$ & $3 / 4$ & $0 / 1$ & $4 / 6$ & $7 / 11$ & $64 \%$ & $81 \% *$ \\
\hline 1.9 \% G & $0 / 4$ & $1 / 4$ & $0 / 4$ & $1 / 12$ & $8 \%$ & $11 \% * * *$ \\
\hline $2 \% \mathrm{DMF}$ & $1 / 2$ & $3 / 3$ & $4 / 7$ & $8 / 12$ & $67 \%$ & 78\%* \\
\hline $1.3 \% \mathrm{EG}$ & $1 / 2$ & $2 / 4$ & $2 / 5$ & $5 / 11$ & $45 \%$ & $45 \%$ \\
\hline
\end{tabular}

Table 7: Per-cycle pregnancy rate (PC) after insemination of jennies with semen of donkey males frozen with $2.2 \%$ glycerol, thawed and either used directly (Control) or after dilution with milk or after washing with milk

\begin{tabular}{ccc}
\hline Semen treatment & No of males & Observed PC \\
\hline Dilution with milk & 5 & $0 / 15(0 \%)$ \\
Control & 2 & $0 / 8(0 \%)$ \\
Washing with milk & 2 & $1 / 8(13 \%)$ \\
\hline
\end{tabular}

Table 8: Per-cycle pregnancy rate (PC) after insemination of jennies with frozen semen of 2 donkey males (with glycerol or with dimethylformamide).

\begin{tabular}{cccccc}
\hline $\begin{array}{c}\text { Cryoprotectant } \\
\left(\text { final } \%^{1}\right)\end{array}$ & $\begin{array}{c}\text { Male 1 } \\
\text { Fri }\end{array}$ & $\begin{array}{c}\text { Male } 2 \\
\text { Lor }\end{array}$ & Total & $\begin{array}{c}\text { Observed } \\
\text { PC }\end{array}$ & $\begin{array}{c}\text { Estimated } \\
\text { PC }^{2}\end{array}$ \\
\hline $\mathrm{G}(2.1 \%)$ & $0 / 7$ & $0 / 9$ & $0 / 16$ & $0 \%$ & $0 \%$ \\
DMF $(2.2 \%)$ & $1 / 13$ & $2 / 15$ & $3 / 28$ & $11 \%$ & $10 \%$ \\
\hline${ }^{1}$ v/v Weighed least square estimates & & & \\
$\mathrm{G}:$ glycerol, DMF : dimethylformamide &
\end{tabular}

